\title{
24
}

\section{ENVIRONMENTAL, SOCIAL, AND GOVERNANCE}

Sir Mark Moody-Stuart

Environmental, social, and governance (ESG) refers to the three categories that enable businesses to measure the real sustainable and societal impact of their outputs. Any business thrives on making or providing goods or services which society needs or wants. The first step towards a socially responsible business is to make sure that there is clarity on this purpose of the company. It is then possible to develop measurements as to how efficiently this is done, not just in terms of cost and quality, but also in the use of natural resources, and to examine whether in addition to the positive elements of the purpose there are negative side effects for society or the environment which need to be mitigated.

Just as important as the underlying purpose is how this purpose is delivered. It is useful to view this in terms of the major Conventions of the United Nations on human rights, working conditions, the environment, and anti-corruption, such as are reflected in the Ten Principles of the UN Global Compact ${ }^{1}$.

1 www.unglobalcompact.org/what-is-gc/mission/principles. 
In 2015, the General Assembly of the United Nations unanimously approved 17 Sustainable Development Goals (SDGs), each with subsidiary indicators. These SDGs provide an important checklist for identifying where and to what extent the organisation's purpose contributes to these globally agreed goals. This is not corporate philanthropy; it involves a focus on areas where the company has skills related to its core purpose and business which can be channelled for the wider benefit of society.

Priorities vary in relation to different stakeholders, whether workers in the organisation or its supply chain, consumers of its products, its shareholders, or the national priorities of the countries where it operates, and includes global priorities. All are important, but the emphasis will vary depending on the nature and spread of an organisation's business. Making sure that the company is effectively considering, addressing, and reporting on its social and environmental responsibilities and performance is very important to the success of a company and to building the trust with different elements of society on which such success ultimately depends.

\section{Questions to ask}

- Has the purpose of the organisation's business and its overall contribution to society been established through discussion widely within the organisation and taking into account the views of external stakeholders?

- Has this purpose been discussed and agreed with the board and is it clear?

- Have all groups touched or impacted by the organisation's activities in delivering its purpose been identified - workers, supply chain, consumers, operational neighbours, shareholders, and governments?

- Have both the positive and negative impacts of the organisation's activities been identified?

- Have the organisation's activities, both its core purpose and activities to deliver this, been mapped against the UN SDGs?

- Has the organisation identified those SDGs to which its core purpose has particular relevance, in addition to those SDGs to which every organisation should be making a contribution?

- Are there modifications which could be made to the organisation's activities, and even its purpose, which could increase alignment with the SDGs without significantly impacting other objectives negatively? 
- To what extent has a similar analysis been made for its supply chain?

- Have adequate steps been taken to encourage and ensure that suppliers are living up to their own responsibilities?

- Are all material impacts measured, using for example indicators of the Global Reporting Initiative?²

- Are the trends in these indicators positive or negative, and how do they benchmark against others in the industry?

- Have targets been set, with clear time frames for delivery?

- Is attention paid not just to the delivery of targets but to how they are delivered?

- Is the delivery in line with the company's stated values?

- Is the delivery undertaken in line with principles such as those of the UN Global Compact, in line with the major UN Conventions on human rights, the environment, working conditions, and anti-corruption?

- Is the organisation reporting publicly in an integrated and transparent way on its performance, so that stakeholders can see how the corporate purpose is being delivered, positive impacts enhanced, and negative impacts ameliorated?

- Are these public reports transparent on both positive and negative impacts of the organisation's activities?

- Does the organisation undertake special efforts to explain to different stakeholders, including shareholders, how an integrated approach is in the long-term interest of all stakeholders and hence to the health of the company?

- Does the organisation undertake regular surveys of stakeholders, both internal and external, to evaluate the alignment of performance both with the company's stated values and with stakeholder needs and aspirations?

- In such surveys, is there appropriate use of independent third parties, including civil society organisations, to ensure frank responses?

- Is the organisation taking full advantage of the work done by other companies and civil society organisations in developing voluntary standards and practical guidance in many areas and the lessons that can be learned from these (for example, the UN Guiding Principles on Business and Human Rights, the Extractive Industries Transparency

2 www.globalreporting.org/. 
Initiative, principles for sustainable trade in various commodities, the Voluntary Principles for Security and Human Rights, and other elements of the World Bank/International Finance Corporation Performance Standards)?

- When dealing with communities neighbouring the organisation's operations, has an independent civil society partner been used to check on their community priorities rather than what might appear to executives to be most needed?

- Has the same civil society partner worked to ensure that the community is aligned in their views and that the governance structures in the community are such that views expressed are not just from one part of the community, for example, an unrepresentative leadership?

- Is the organisation transparent about payment of taxes and whether tax is paid in each country aligns with work actually done?

- Have the financial flows of the organisation in each country of operation been analysed and reported on in terms of revenue generated, investment and dividend flows, taxes paid, employment generated, and so on, and does the distribution of these flows appear to fairly reflect activities and use of resources?

- Does leadership meet and openly engage with critics and try and understand the basis for their criticism, and not just dismiss views as ill-informed?

- Does leadership make efforts to join with others in business and civil society to assist governments to build fiscal and regulatory frameworks which are in the interests of society as a whole and not merely influenced by individual corporate or industry interests?

- While pure philanthropy is not and should not be the driving force for the organisation's approach to social responsibility, does the budget allow for local operations to contribute to local citizenship activities which build local community relationships although they may be unrelated to global programmes?

- Does the organisation support and encourage individual or collective voluntary activities by employees, in particular but not exclusively, using their professional skills and abilities? 